\title{
Characterization of the Surface Layer of Ag/W Electrical Contacts
}

\author{
H. Yu, Y. Sun, S. P. Alpay and M. Aindow
}

Department of Materials Science and Engineering, Institute of Materials Science, University of Connecticut, Unit 3136, 97 North Eagleville Road, Storrs, CT 06269-3136, USA

Materials for electrical contacts in circuit breakers must meet a stringent set of property requirements including excellent thermal conductivity, electrical conductivity, corrosion resistance and arc erosion resistance [1]. In most cases, no simple metallic alloy can meet these requirements, and metal-matrix composites must be used instead. The metallic matrix phase in such composites is usually silver, due to its excellent electrical properties, and the most common reinforcements used are Mo, W and WC [2]. The properties of the composite depend critically on microstructural parameters such as phase volume fractions, morphologies and distributions. Here we present data from our studies on Ag/W composite contacts and some of the potential complications in the characterization of such materials are discussed.

A series of commercial powder-processed $\mathrm{Ag} / \mathrm{W}$ contacts was evaluated using electron microscopy techniques. Particular attention was paid to the character of the contact surface since this dictates the arc erosion behavior during switching [3]. The contact surfaces were examined using backscattered electron (BSE) imaging in a JEOL 6335F field-emission SEM to reveal the distribution of the Ag and W phases. The results were found to be remarkably sensitive to the accelerating voltage used as shown in Figure 1. This figure is a selection of four BSE images obtained from the same region of a contact surface at different accelerating voltages. The bright regions are the $\mathrm{W}$, the darker regions are the Ag, and the black features are residual surface porosity from the powder processing. The surface porosity is revealed most clearly at the lowest accelerating voltage $(5 \mathrm{kV}$, Fig 1a) as expected due to differences in the excitation volume. Surprisingly, there are also dramatic differences in the apparent volume fraction of the $\mathrm{W}$ phase. There appears to be far more $\mathrm{W}$ at $20 \mathrm{kV}$ (Fig 1d) than at $5 \mathrm{kV}$ (Fig 1a), although in all cases this is significantly less than the nominal volume fraction of $50 \%$ for this contact material.

The origins of this effect are revealed clearly in cross-sectional SEM and TEM images (e.g. Figs $2 \& 3$, respectively). The BSE SEM images obtained from metallographic cross-sections through these contacts reveal the presence of an Ag layer up to $5 \mu \mathrm{n}$ in thickness covering most of the contact surface. Thin sections were cut from the surface using FEI Strata 400S DualBeam FIB and imaged in a JEOL JEM-2010 FasTEM at an accelerating voltage of $200 \mathrm{kV}$. The TEM images show that the Ag surface layer has a much finer grain structure than the Ag regions within the composite and that even the "exposed" W is covered by a nanocrystalline Ag layer of up to 50nm in thickness. Thus the apparent variation in surface $\mathrm{W}$ content also arises due to differences in excitation volume with accelerating voltage (e.g. [4]). [5]

\section{References:}

[1] P. G. Slade, IEEE Trans. Compon., Hybrids, Manuf. Technol. CHMT-9 (1986) 3.

[2] C. H. Leung, P. C. Wingert and H. J. Kim, ibid(1986) 86.

[3] J. W. Mcbride, K. J. Cross and S. M. Abu Sharkh, IEEE Trans. Compon. Packag. Manuf. Technol.

Part A 19 (1996) 87.

[4] K. Kanaya and S. Okayama, J. Phys. D: Appl. Phys. 5 (1972) 43.

[5] This work was supported by a grant from GE Energy Management. 

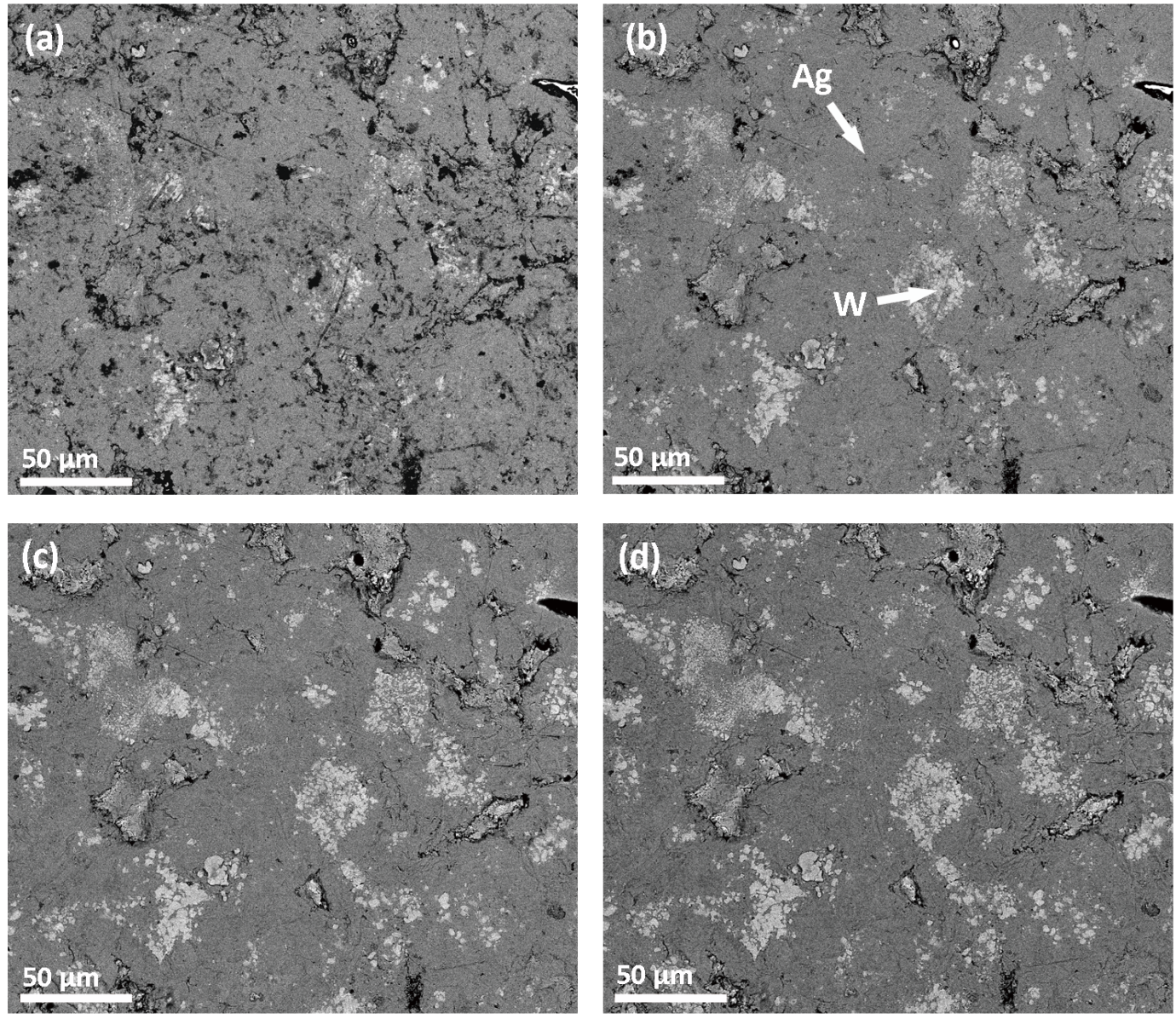

Figure 1. BSE SEM images of the surface of an $\mathrm{Ag} / \mathrm{W}$ electrical contact obtained at accelerating voltages of: (a) $5 \mathrm{kV}$, (b) $10 \mathrm{kV}$, (c) $15 \mathrm{kV}$ and (d) $20 \mathrm{kV}$.

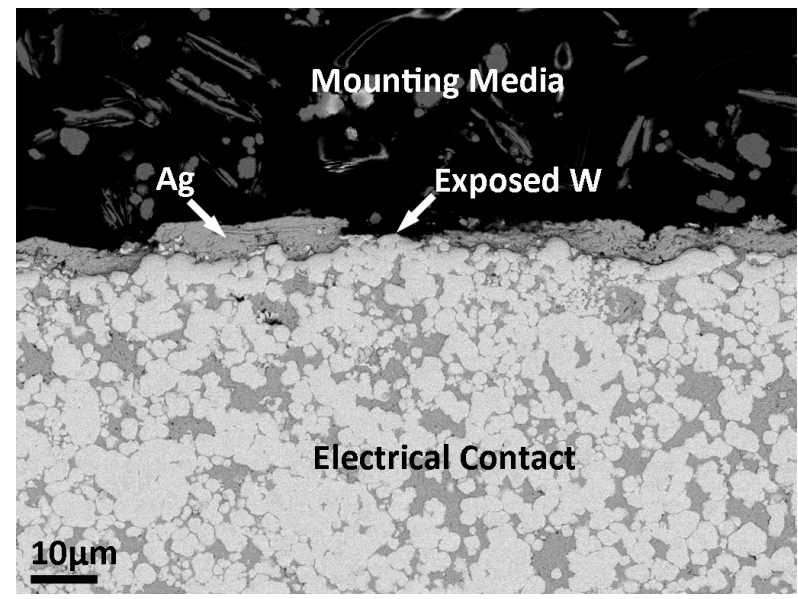

Figure 2. BSE SEM image of a cross-section from the surface of an $\mathrm{Ag} / \mathrm{W}$ electrical contact.

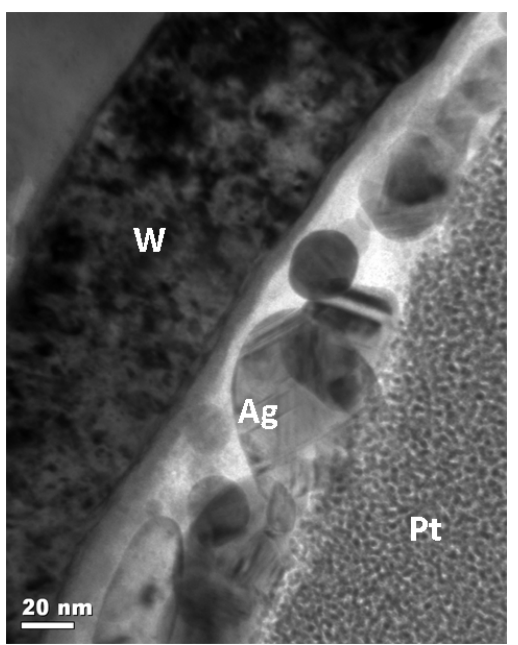

Figure 3. Bright field TEM image of a FIB-cut cross-section. 